\title{
Distribution of the human leukocyte antigen class II alleles in Brazilian patients with chronic hepatitis $\mathrm{C}$ virus infection
}

\author{
D.B. Corghi ${ }^{1}$, N.S.L. Gonçales ${ }^{1,2}$, S.B.D. Marques ${ }^{2}$ and F.L. Gonçales Jr. ${ }^{1}$ \\ ${ }^{1}$ Grupo de Estudo das Hepatites, Disciplina de Moléstias Infecciosas, Departamento de Clínica Médica, \\ Faculdade de Ciências Médicas, Universidade Estadual de Campinas, Campinas, SP, Brasil \\ ${ }^{2}$ Centro de Hematologia e Hemoterapia, Universidade Estadual de Campinas, Campinas, SP, Brasil
}

Correspondence to: F.L. Gonçales Jr., Grupo de Estudo das Hepatites, Disciplina de Moléstias Infecciosas, Departamento de Clínica Médica, Faculdade de Ciências Médicas, UNICAMP, Rua Tessália Vieira de Camargo, 126, 13083-970 Campinas, SP, Brasil

Fax: +55-19-3521-7727. E-mail: flgj@uol.com.br

\begin{abstract}
Hepatitis $\mathrm{C}$ virus (HCV) infection is a global medical problem. The current standard of treatment consists of the combination of peginterferon plus ribavirin. This regimen eradicates $\mathrm{HCV}$ in $55 \%$ of cases. The immune response to HCV is an important determinant of disease evolution and can be influenced by various host factors. HLA class II may play an important role in immune response against HCV. The objective of the present study was to determine the distribution of HLA class II (DRB1 and DQB1) alleles, their association with chronic HCV infection and their response to interferon therapy. One hundred and two unrelated white Brazilian patients with chronic HCV infection, 52 responders ( 45 males and 7 females) and 50 non-responders (43 males and 7 females) to antiviral treatment, were included in the study. Healthy Brazilian bone marrow donors of Caucasian origin from the same geographic area constituted the control group (HLA-DRB1, N = 99 and HLA-DQB1, N = 222 individuals). HLA class II genotyping was performed using a low-resolution DRB1, DQB1 sequence-specific primer amplification. There were higher frequencies of HLA-DRB1*13 (26.5 vs 14.1\%) and HLA-DQB1*02 (52.9 vs 38.7\%) in patients compared with controls; however, these were not significantly different after $\mathrm{P}$ correction $(\mathrm{PC}=0.39$ and $\mathrm{PC}=0.082$, respectively). There was no significant difference between the phenotypic frequencies of HLA-DRB1 (17.3 vs 14.0\%) and HLA-DQB1 alleles in responder and non-responder HCV patients. The HLA-DRB $1^{*} 07$ allele was significantly more common in HCV patients (33.3 vs $\left.12.1 \%\right)$ than in controls $(\mathrm{Pc}=0.0039)$, suggesting that the $\mathrm{HLA}-\mathrm{DRB} 1^{*} 07$ allele is associated with chronic HCV infection.
\end{abstract}

Key words: HLA class II; HLA DR/DQ; HLA genotyping PCR; Hepatitis C virus; Chronic hepatitis C; Interferon treatment

Research supported by Fundo de Amparo ao Ensino e Pesquisa (FAEP), UNICAMP. Publication supported by FAPESP.

Received September 20, 2007. Accepted September 5, 2008

\section{Introduction}

Hepatitis C virus (HCV), first described in 1989, is now recognized as one of the main causes of chronic liver disease worldwide. HCV infection becomes chronic in the majority of cases, with only $10-20 \%$ of those infected not developing persistent viremia. The immune response to HCV may be an important determinant of disease resolution and can be influenced by a number of host factors. It is not clear why many of these individuals remain asymptomatic, without significant liver damage, while others develop severe liver disease, progressing to cirrhosis and hepatocellular carcinoma, or why only some of those who are treated respond to interferon (IFN) therapy (1). An association between major histocompatibility complex $(\mathrm{MHC})$ alleles and clinical outcome of viral infection has been reported in hepatitis B virus (2) and human immunodeficiency virus (HIV) infection (3). Genetic association studies have strongly suggested that the human leukocyte antigen (HLA) class II restricted response may be important in the immunological 
control of HCV disease outcome, although the implicated genes differ (4-7). Patients carrying the DQB1*0301 (or DRB1*1101), an allele with close linkage disequilibrium, have been consistently found $(6,7)$, particularly in a previous large study (8), to have an increased chance of having cleared the virus spontaneously and, also, a weaker association with clearance after IFN- $\alpha$ treatment. Other associations have also been reported; for example, a British and French group reported an association of HLA-DRB1*1101 and HLA-DQB1*0301 with HCV clearance in Caucasian populations, and there was no association of HLA antigens with persistent HCV infection (5,9). In contrast, a German study found an association of HLA-DRB $1{ }^{*} 0301$ with chronic HCV (10). In addition, a Japanese group reported association of HLA-DRB1*0405 and HLA-DQB1*0401 with chronic liver disease due to HCV, and an association of HLADRB1*1101, HLA-DRB1*1302, and HLA-DQB1*0604 with HCV carriers has been reported (11). A Thai study demonstrated that HLA-DRB1 0301 and HLA-DQB1 0201 are associated with persistent $\mathrm{HCV}$ infection, whereas HLADRB1*0701 and HLA-DQA1*0201 are associated with protection against HCV infection (12). In contrast, a Polish study showed the HLA-DRB1*0701-DQA1*0201-DQB1*02 haplotype to be associated with both chronic infection and response to IFN- $\alpha$ (1). This inconsistency could be due to the small size of some studies, ethnic differences, or HCV genetic variability.

There has been little research in this field in Brazil, although $\mathrm{HCV}$ infection occurs at a moderately high rate in the population. A study with a highly admixed Brazilian population (104 HCV-antibody-positive patients and 166 healthy controls) suggested an association of spontaneous HCV clearance with HLA allele groups DRB*01 01 and DQB ${ }^{*} 0103$ (13). However, no data were found in the literature correlating the association between Brazilian HCV patients and both HLA and response to IFN treatment.

We determined the distribution of HLA class II alleles in patients with chronic hepatitis $\mathrm{C}$ using a low-resolution PCR-sequence-specific primer (SSP) method to assess whether MHC class II alleles were associated with HCV infection and with their response to IFN therapy.

\section{Subjects and Methods}

\section{Subjects}

One hundred and two unrelated, Caucasian Brazilian patients (88 males, 14 females; mean age $44.3 \pm 11.4$ years; age range 23-72 years), living in Campinas, SP, Southeast Brazil, undergoing IFN- $\alpha$ treatment for chronic $\mathrm{HCV}$ infection followed by the Study Group of Hepatitis at the UNICAMP University Medical School Hospital, were included in this study. The present study was approved by the Faculty of Medical Sciences Ethics Committee and all patients gave their written informed consent. All patients were positive for both HCV antibodies (enzyme immunoassay, 4th generation, Murex, South Africa) and serum HCV RNA (RT-PCR, Cobas Amplicor HCV, version 2.0, Roche, USA) and were negative for both hepatitis $B$ virus and HIV. A liver biopsy was indicated in patients with a persistent ( $>6$ months) elevation of alanine aminotransferase 1.5 times above the upper normal limit, with positive reactions to HCV antibodies and to HCV RNA testing in serum. Eighty-three patients were submitted to biopsy; among these, 75 patients showed histological evidence of chronic hepatitis $C$. The stage of fibrosis was determined according to METAVIR score, which varied from 0 to 4 ( $F 0=$ no fibrosis; $F 1=$ portal fibrosis without septa; F2 = portal fibrosis with few septa; F3 = septal fibrosis, without cirrhosis; F4 = cirrhosis) (14). Other causes of chronic liver disease that were not HCV were excluded.

In 98 patients, HCV genotyping was carried out by reverse hybridization (InnoLipa, Innogenetics, Belgium). After HCV genotyping, all patients were submitted to an interferon therapy. Forty-six patients with genotype 1 and 4 patients considered as genotype not defined (mix), received 1 year of standard therapy (IFN- $\alpha-2 a$ or $-2 b$ plus ribavirin), while 52 patients with genotype 3 received 6 months of antiviral therapy, according to treatment guidelines (15-17). Responder and non-responder patients were included in this study, about one year after the end of interferon therapy. Sustained virological responders were defined as patients who presented clearance of serum HCV-RNA at the end of treatment and 6 months thereafter (responder patients). Using this criterium, 52 patients were considered to be responders and 50 patients were classified as non-responders (Table 1).

Healthy unrelated Caucasian Brazilian bone marrow donors from the same geographic area constituted the control group (HLA class II DRB1: $\mathrm{N}=99 ; 53$ males, 46 females; mean age $34.3 \pm 11.4$ years; age range $25-47$ years; HLA class II DQB1: $\mathrm{N}=222$; 136 males, 86 females; mean age $35.4 \pm 9.7$ years; age range $27-46$ years)

\section{HLA class II genotyping}

Genomic DNA was immediately isolated from fresh peripheral blood cells using a commercial DNA isolation kit (Puregene ${ }^{\mathrm{TM}}$ Gentra Systems, USA), according to manufacturer instructions. HLA class II alleles were determined using Micro SSPTM HLA DNA typing trays (One Lambda, USA). HLA class II genotyping was performed using a lowresolution DRB1, DQB1 SSP amplification, according to manufacturer instructions, in all individuals evaluated in this study (patients and controls). 
After PCR processing, the amplified DNA fragments were separated by agarose gel electrophoresis and visualized by staining with ethidium bromide and exposure to ultraviolet light; the results were documented by Polaroid photography. Interpretation of PCR-SSP results was based on the presence or absence of a specific amplified DNA fragment. Because amplification during the PCR may be adversely affected by various factors (pipetting errors, poor DNA quality, presence of inhibitors, etc.), an internal control primer pair was included in every PCR product. The control primer pair amplifies a conserved region of the human $B$-globin gene, which is present in all DNA samples and is used to check the integrity of the PCR product. Whenever there is a positive specific typing band amplification of an HLA allele, the product of the internal control primer pair may be weak or absent due to the differences in concentration and melting temperatures between the specific primer pairs and the internal control primer pair. The amplified DNA fragments of the specific HLA primer pairs are smaller than the product of the internal control primer pair, but they are larger than the diffuse, unincorporated primer band. Thus, a positive reaction for a specific HLA allele or allele group is visualized on the gel as an amplified DNA fragment between the internal control product band and the unincorporated primer band.

\section{Statistical analysis}

Frequency of alleles was compared between groups by the $\chi^{2}$ test with either the Yates correction or the Fisher exact test. For all tests, $\mathrm{P} \leq 0.05$ was considered to be significant, and the significant $P$ value was corrected $(\mathrm{Pc}$; Bonferroni's correction) for the number of alleles detected at each locus.

\section{Results}

Selected characteristics of the patient cohort are presented in Table 1. No differences between the two groups in relation to age, gender and genotype were found, with the exception that $\mathrm{F} 1$ was more frequent in sustained responders ( 30 vs $4.6 \% ; \mathrm{P}<0.05$ ), and $\mathrm{F} 3$ more frequent in non-responders (34.9 vs $7.5 \% ; \mathrm{P}<0.05)$. As observed among non-responder patients to IFN therapy, there were $23 / 43(53.5 \%)$ with significant fibrosis (F3 and F4) compared to $5 / 40(12.5 \%)$ responder patients $(P<0.05)$. Among responder patients to IFN therapy, there was no significant fibrosis (F0-F2) in 35/40 (87.5\%), while no significant fibrosis was encountered in 20/43 (46.5\%) of nonresponder patients $(P<0.05)$.

Among HLA-DRB1 alleles, the frequencies of HLADRB1 ${ }^{*} 13$ and HLA-DRB1*07 $(P=0.0003, P c=0.003)$ were significantly higher in the patients with $\mathrm{HCV}$ infection than in the control group. However, after $\mathrm{P}$ correction (Bonferroni's correction), the frequency of the HLADRB ${ }^{*} 13$ allele was not significantly higher in the patients (Table 2).

Among HLA-DQB1 alleles, the frequency of the HLADQB ${ }^{*} 02$ was also significantly higher $(P<0.05)$ in the

Table 1. Characteristics of patients with chronic hepatitis $C$ virus (HCV) infection and their response to IFN- $\alpha$ therapy according to fibrosis grade (Metavir score) and HCV genotype.

\begin{tabular}{lcc}
\hline Characteristics & $\begin{array}{c}\text { Sustained responders } \\
(\mathrm{N}=52)\end{array}$ & $\begin{array}{c}\text { Non-responders } \\
(\mathrm{N}=50)\end{array}$ \\
\hline Age (mean $\pm \mathrm{SD})$ & $43.2 \pm 11.4$ & $44.1 \pm 9.2$ \\
Gender (male/female) & $45 / 7$ & $43 / 7$ \\
Liver biopsy (N = 83) & & \\
F0 & $6 / 40(15 \%)$ & $2 / 43(4.6 \%)$ \\
F1 & $12 / 40(30 \%)$ & $2 / 43(4.6 \%)^{*}$ \\
F2 & $17 / 40(42.5 \%)$ & $16 / 43(37.3 \%)$ \\
F3 & $3 / 40(7.5 \%)$ & $15 / 43(34.9 \%)^{*}$ \\
F4 & $2 / 40(5.0 \%)$ & $8 / 43(18.6 \%)$ \\
HCV genotype $(\mathrm{N}=98)$ & & \\
1 & $19(39.6 \%)$ & $27(54 \%)$ \\
3 & $29(60.4 \%)$ & $23(46 \%)$ \\
\hline
\end{tabular}

Data are reported as number with percent within parentheses. Percent was calculated on the number of subjects in the group. Metavir score: $\mathrm{F} 0=$ no fibrosis; $\mathrm{F} 1=$ portal fibrosis without septa; $\mathrm{F} 2$ = portal fibrosis with few septa; F3 = septal fibrosis without cirrhosis; $\mathrm{F} 4=$ cirrhosis. ${ }^{*} \mathrm{P} \leq 0.005$ compared to sustained responders ( $\chi^{2}$ test with Yates' correction).

Table 2. Distribution of human leukocyte antigen class II (HLADRB1) phenotype frequencies in patients with chronic hepatitis $\mathrm{C}$ virus (CHCV) infection and in healthy control subjects.

\begin{tabular}{rccl}
\hline HLA-DRB1 & $\begin{array}{c}\text { Control } \\
(\mathrm{N}=99)\end{array}$ & $\begin{array}{c}\text { CHCV patients } \\
(\mathrm{N}=102)\end{array}$ & $\begin{array}{c}\text { OR } \\
(95 \% \mathrm{CI})\end{array}$ \\
\hline 1 & $24(24.1 \%)$ & $16(15.7 \%)$ & $0.58(0.27-1.24)$ \\
15 & $14(14.1 \%)$ & $16(15.7 \%)$ & $1.13(0.49-2.63)$ \\
16 & $3(3 \%)$ & $9(8.8 \%)$ & $3.1(0.74-14.93)$ \\
3 & $18(18.2 \%)$ & $25(24.5 \%)$ & $1.46(0.7-3.05)$ \\
4 & $15(15.1 \%)$ & $23(22.5 \%)$ & $1.63(0.75-3.56)$ \\
11 & $26(26.3 \%)$ & $25(24.5 \%)$ & $0.91(0.46-1.81)$ \\
12 & $4(4 \%)$ & $1(1 \%)$ & $0.24(0.01-2.29)$ \\
13 & $14(14.1 \%)$ & $27(26.5 \%)$ & $2.19(1.01-4.76)$ \\
14 & $8(8.1 \%)$ & $4(3.9 \%)$ & $0.46(0.11-1.78)$ \\
7 & $12(12.1 \%)$ & $34(33.3 \%)^{*}$ & $3.63(1.66-8.05)$ \\
8 & $6(6.1 \%)$ & $7(6.9 \%)$ & $0.97(0.15-6.19)$ \\
9 & $3(3 \%)$ & $3(2.9 \%)$ & $1.14(0.33-4.01)$ \\
10 & $7(7.1 \%)$ & $3(2.9 \%)$ & $0.4(0.08-1.78)$ \\
\hline
\end{tabular}

Data are reported as number with percent of total subjects in the group within parentheses. $\mathrm{Pc}$ (Bonferroni's correction) $=\mathrm{P} \times 13$ corresponding to the number of HLA allelic groups tested (13 DRB1). Pc $<0.004$ compared to controls (Fisher exact test). 
Table 3. Distribution of human leukocyte antigen class II (HLADQB1) phenotype frequencies in patients with chronic hepatitis $\mathrm{C}$ virus (CHCV) infection and in healthy control subjects.

\begin{tabular}{lrcc}
\hline HLA-DQB1 & \multicolumn{3}{c}{ Number of alleles $\%$} \\
\cline { 2 - 5 } & $\begin{array}{c}\text { Control } \\
(\mathrm{N}=222)\end{array}$ & $\begin{array}{c}\text { CHCV patients } \\
(\mathrm{N}=102)\end{array}$ & $\begin{array}{c}\text { OR } \\
(95 \% \mathrm{Cl})\end{array}$ \\
\hline 2 & $86(38.7 \%)$ & $54(52.9 \%)^{*}$ & $1.78(1.08-2.94)$ \\
3 & $119(53.6 \%)$ & $52(51 \%)$ & $0.9(0.55-1.48)$ \\
4 & $24(10.8 \%)$ & $6(5.9 \%)$ & $0.52(0.18-1.39)$ \\
5 & $79(35.6 \%)$ & $36(35.3 \%)$ & $0.99(0.59-1.66)$ \\
6 & $85(38.3 \%)$ & $39(38.2 \%)$ & $1.0(0.59-1.66)$
\end{tabular}

Data are reported as number with percent of total subjects in the group within parentheses. Pc (Bonferroni's correction) $=\mathrm{P} \times 5$ corresponding to the number of HLA allelic groups tested (5 DQB1). ${ }^{*} P<0.017$ compared to controls $\left(\chi^{2}\right.$ test with Yates' correction), $\mathrm{Pc}>0.05$ compared to controls ( $\chi^{2}$ test with Yates' correction).

patients with HCV infection than in the control group. However, this difference was not significant after $\mathrm{P}$ correction (Table 3). Also, there was no significant difference between the phenotype frequencies of HLA-DRB1 and HLA-DQB1 alleles in patients who were sustained responders and non-responders $(P>0.05)$. Analysis of the relationship between response to IFN therapy and all haplotypes in linkage disequilibrium indicated that there were no statistically significant differences observed between the groups studied.

\section{Discussion}

HLA class II may play an important role in host immune reactions against viral infection because it is a key protein for antigen presentation by antigen-presenting cells to $\mathrm{T}$ helper cells. Since T-helper cells recognize peptides presented by HLA class II molecules, it is reasonable to investigate HLA class II (DRB1 and DQB1) gene polymorphisms in patients with HCV infection $(6,18,19)$. There is also strong evidence $(8,13)$ that class II genes are involved in control of $\mathrm{HCV}$, notably a protective effect of HLADQB1*0301 (and/or DRB1*1101, which is in close linkage disequilibrium). A study had observed that HLA-DQB1*0301 was weakly associated with viral clearance in combined ethnic groups, but was strong in black subjects (20). In white subjects, viral clearance was associated with DRB1*0101 and its DQB1*0501 haplotype, whereas viral persistence was associated with DRB1*0301 $(6,9,20)$.

$A$ recent study on Caucasian and African Americans confirmed the previously reported associations between
HCV clearance and two HLA types (DQB ${ }^{*} 03$, DRB1*11) while identifying a new association with DRB3*02. However, these associations were identified only among the Caucasian patients and not among African American patients (21).

These data support a role for class II alleles in the immune response to HCV and underscore the importance of studying genetic association in an ethnically diverse cohort.

The present study was specifically designed to determine association, if any, of host HLA class II genotype profile of chronic HCV patients with a response of HLAhepatitis $\mathrm{C}$ to IFN therapy in a Brazilian population of Caucasian origin. We detected higher frequencies of HLADRB1*13 and HLA-DQB1*02 in HCV patients but after Bonferroni's correction the $P$ values were not statistically significant. The HLA-DRB1 ${ }^{*} 07$ allele was significantly more frequent in chronic HCV patients than in controls after applying Bonferroni's correction. Our data for the HLA DRB $1^{*} 07$ allele are similar to those reported in a Polish study in which the HLA-DRB1*0701-DQA 1*0201-DQB1*02 haplotype was associated with both chronic infection and response to IFN- $\alpha$ (1). In another study of Irish women, a significant reduction in the frequency of HLA-DQB1*0501 was identified in the presence of HLA-DRB1*0701 in individuals chronically infected with $\mathrm{HCV}$ (22). An association between the alleles HLA-DRB1 0701 and HLA-DRB4*0101 with persistent infection was also detected in another study of European patients (8). The HLA-DRB1*0701 allele has been reported to be associated with persistent infection by hepatitis $B$ virus, but until the present study not with hepatitis $C(2)$. In another study, of a Thai population (12), the HLA-DRB $1{ }^{*} 0701$ and HLA-DQA $1{ }^{*} 0201$ alleles were significantly decreased in the HCV-infected individuals compared with the uninfected controls. It was suggested that these alleles are associated with protection against HCV infection. In a French study, higher frequencies of HLA-DQB $1{ }^{*} 0301$ and HLA-DRB1*1101 were reported for patients with transient hepatitis than for those with chronic hepatitis (9) and an Italian study found that the haplotypes HLA-DRB1*1104, HLA-DQA1*0501, HLA$\mathrm{DQB1}{ }^{*} 0301$ were associated with low frequency of $\mathrm{HCV}$ infections, whereas HLA-DQA1*0201-DQB1*0201 predisposed patients to chronic hepatitis (23). As may be observed, important differences exist between the studies in relation to the alleles of class II and their protective effects and associations with persistent and chronic infection by $\mathrm{HCV}$. Our data and those for other countries cited here support a role for class II alleles in the immune response to $\mathrm{HCV}$ and underscore the importance of studying genetic associations in the ethnically diverse cohorts. 
$\mathrm{HCV}$ persists in most infected individuals and is responsible for a wide spectrum of chronic liver lesions, ranging from minimal inflammation to cirrhosis or hepatocellular carcinoma. Approximately $20 \%$ of infected patients successfully eliminate the virus (24) while the remainder continues with chronic infection.

Treatment with IFN can improve the natural history of chronic HCV. A number of factors predicting the response to IFN therapy as genotype other than HCV genotype $1 \mathrm{~b}$, lower levels of viremia, and the absence of cirrhosis have been associated with more favorable responses $(25,26)$. Therefore, it is likely that inherited differences in genes regulating immune reactivity may affect individual responses to its therapeutic use $(27,28)$. HLA class II alleles, although consistently associated with the expression of $\mathrm{HCV}$-related liver disease, have failed so far to show any reproducible effect on IFN treatment response in independent studies $(8,29)$. An association of response to IFN with HLA-DR 2 and DRB1*0404 has been reported in Egyptian (30) and Canadian (31) patients, respectively, but in both studies only the biochemical response was evaluated based on the decrease of the alanine aminotransferase level in serum during therapy and not the virological response (clearance of HCV-RNA in serum). A Japanese study that considered virological response found the $\mathrm{DRB} 1^{*} 07$ allele to be closely related to the complete response, whereas $\mathrm{DRB} 1^{*} 04$ showed no response at all (32). A Polish study showed the HLA-DRB1*0701DQA 1*0201-DQB1*02 haplotype to be associated with both chronic infection and response to IFN- $\alpha$ (1). In another study of Taiwanese patients, the alleles HLA-A11, HLA-B51, HLA-Cw15 and HLA-DRB1*15 were positively correlated with a sustained response, whereas HLA-A24 was inversely associated with response to IFN- $\alpha$. The HLA-A11-HLA-DRB1*15 haplotype was strongly associated with a sustained response (33).

However, in the present study of Brazilian patients, we did not detect any difference in the distribution of $\mathrm{MHC}$ class II alleles between responder and non-responder patients. In addition, responder patients had less fibrosis than non-responder patients; thus, fibrosis may influence the response to IFN directly.

\section{References}

1. Wawrzynowicz-Syczewska M, Underhill JA, Clare MA, Boron-Kaczmarska A, McFarlane IG, Donaldson PT. HLA class II genotypes associated with chronic hepatitis $C$ virus infection and response to alpha-interferon treatment in Poland. Liver 2000; 20: 234-239.

2. Almarri A, Batchelor JR. HLA and hepatitis B infection. Lancet 1994; 344: 1194-1195.

3. Ndung'u T, Gaseitsiwe S, Sepako E, Doualla-Bell F, Peter $\mathrm{T}$, Kim S, et al. Major histocompatibility complex class II (HLA-DRB and -DQB) allele frequencies in Botswana: association with human immunodeficiency virus type 1 infection. Clin Diagn Lab Immunol 2005; 12: 1020-1028.

4. Tibbs C, Donaldson P, Underhill J, Thomson L, Manabe K, Williams R. Evidence that the HLA DQA $1{ }^{*} 03$ allele confers protection from chronic HCV-infection in Northern European Caucasoids. Hepatology 1996; 24: 1342-1345.

5. Alric L, Fort M, Izopet J, Vinel JP, Charlet JP, Selves J, et al. Genes of the major histocompatibility complex class II influence the outcome of hepatitis C virus infection. Gastroenterology 1997; 113: 1675-1681.

6. Cramp ME, Carucci $P$, Underhill J, Naoumov NV, Williams $\mathrm{R}$, Donaldson PT. Association between HLA class II genotype and spontaneous clearance of hepatitis $C$ viraemia. $J$ Hepatol 1998; 29: 207-213.

7. Mangia A, Gentile R, Cascavilla I, Margaglione M, Villani MR, Stella F, et al. HLA class II favors clearance of HCV infection and progression of the chronic liver damage. $J$ Hepatol 1999; 30: 984-989.

8. Thursz M, Yallop R, Goldin R, Trepo C, Thomas HC. Influence of MHC class II genotype on outcome of infection with hepatitis $C$ virus. The HENCORE group. Hepatitis C European Network for Cooperative Research. Lancet 1999; 354: 2119-2124.

9. Minton EJ, Smillie D, Neal KR, Irving WL, Underwood JC, James V. Association between MHC class II alleles and clearance of circulating hepatitis $C$ virus. Members of the Trent Hepatitis C Virus Study Group. J Infect Dis 1998; 178: 39-44.

10. Hohler T, Gerken G, Notghi A, Knolle P, Lubjuhn R, Taheri $\mathrm{H}$, et al. MHC class II genes influence the susceptibility to chronic active hepatitis C. J Hepatol 1997; 27: 259-264.

11. Kuzushita N, Hayashi N, Moribe T, Katayama K, Kanto T, Nakatani S, et al. Influence of HLA haplotypes on the clinical courses of individuals infected with hepatitis $C$ virus. Hepatology 1998; 27: 240-244.

12. Vejbaesya S, Songsivilai $S$, Tanwandee $T$, Rachaibun $S$, Chantangpol R, Dharakul T. HLA association with hepatitis C virus infection. Hum Immunol 2000; 61: 348-353.

13. Cursino-Santos JR, Donadi EA, Martinelli AL, LouzadaJunior $P$, Martinez-Rossi NM. Evolution of hepatitis $C$ virus infection under host factor influence in an ethnically complex population. Liver Int 2007; 27: 1371-1378.

14. Bedossa P, Poynard T. An algorithm for the grading of activity in chronic hepatitis C. The METAVIR Cooperative Study Group. Hepatology 1996; 24: 289-293.

15. Seeff LB, Hoofnagle JH. National Institutes of Health Consensus Development Conference: management of hepatitis C: 2002. Hepatology 2002; 36: S1-S2.

16. Manns MP, McHutchison JG, Gordon SC, Rustgi VK, Shiffman M, Reindollar R, et al. Peginterferon alpha-2b plus 
ribavirin compared with interferon alpha- $2 \mathrm{~b}$ plus ribavirin for initial treatment of chronic hepatitis C: a randomised trial. Lancet 2001; 358: 958-965.

17. Fried MW, Shiffman ML, Reddy KR, Smith C, Marinos G, Goncales FL Jr, et al. Peginterferon alpha-2a plus ribavirin for chronic hepatitis C virus infection. N Engl J Med 2002; 347: 975-982.

18. Ferrari C, Valli A, Galati L, Penna A, Scaccaglia P, Giuberti $\mathrm{T}$, et al. T-cell response to structural and nonstructural hepatitis $C$ virus antigens in persistent and self-limited hepatitis C virus infections. Hepatology 1994; 19: 286-295.

19. Donaldson PT. The interrelationship between hepatitis $C$ virus and HLA. Eur J Clin Invest 1999; 29: 280-283.

20. Thio CL, Thomas DL, Goedert JJ, Vlahov D, Nelson KE, Hilgartner MW, et al. Racial differences in HLA class II associations with hepatitis $C$ virus outcomes. $J$ Infect Dis 2001; 184: 16-21.

21. Harris RA, Sugimoto $K$, Kaplan DE, Ikeda F, Kamoun M, Chang KM. Human leukocyte antigen class II associations with hepatitis $C$ virus clearance and virus-specific CD4 T cell response among Caucasians and African Americans. Hepatology 2008; 48: 70-79.

22. Fanning LJ, Levis J, Kenny-Walsh E, Wynne F, Whelton M, Shanahan F. Viral clearance in hepatitis C (1b) infection: relationship with human leukocyte antigen class II in a homogeneous population. Hepatology 2000; 31: 1334-1337.

23. Zavaglia C, Martinetti M, Silini E, Bottelli R, Daielli C, Asti M, et al. Association between HLA class II alleles and protection from or susceptibility to chronic hepatitis C. J Hepatol 1998; 28: 1-7.

24. Yenigun A, Durupinar B. Decreased frequency of the HLADRB1*11 allele in patients with chronic hepatitis $C$ virus infection. J Virol 2002; 76: 1787-1789.

25. McHutchison JG, Gordon SC, Schiff ER, Shiffman ML, Lee WM, Rustgi VK, et al. Interferon alpha-2b alone or in combination with ribavirin as initial treatment for chronic hepatitis
C. Hepatitis Interventional Therapy Group. N Engl J Med 1998; 339: 1485-1492.

26. Lauer GM, Walker BD. Hepatitis $C$ virus infection. $N$ Engl J Med 2001; 345: 41-52.

27. Botarelli $P$, Brunetto $M R$, Minutello MA, Calvo $P$, Unutmaz $D$, Weiner AJ, et al. T-lymphocyte response to hepatitis C virus in different clinical courses of infection. Gastroenterology 1993; 104: 580-587.

28. Airoldi A, Zavaglia C, Silini E, Tinelli C, Martinetti M, Asti M, et al. Lack of a strong association between HLA class II, tumour necrosis factor and transporter associated with antigen processing gene polymorphisms and virological response to alpha-interferon treatment in patients with chronic hepatitis C. Eur J Immunogenet 2004; 31: 259-265.

29. Alric L, Izopet J, Fort M, Vinel JP, Fontenelle P, Orfila C, et al. Study of the association between major histocompatibility complex class II genes and the response to interferon alpha in patients with chronic hepatitis $\mathrm{C}$ infection. Hum Immunol 1999; 60: 516-523.

30. Almarri A, El Dwick N, Al Kabi S, Sleem K, Rashed A, Ritter $M A$, et al. Interferon-alpha therapy in HCV hepatitis: HLA phenotype and cirrhosis are independent predictors of clinical outcome. Hum Immunol 1998; 59: 239-242.

31. Sim H, Wojcik J, Margulies M, Wade JA, Heathcote J. Response to interferon therapy: influence of human leucocyte antigen alleles in patients with chronic hepatitis C. J Viral Hepat 1998; 5: 249-253.

32. Jiao J, Wang JB. Hepatitis C virus genotypes, HLA-DRB alleles and their response to interferon-alpha and ribavirin in patients with chronic hepatitis C. Hepatobiliary Pancreat Dis Int 2005; 4: 80-83.

33. Yu ML, Dai CY, Chen SC, Chiu CC, Lee LP, Lin ZY, et al. Human leukocyte antigen class I and II alleles and response to interferon-alpha treatment, in Taiwanese patients with chronic hepatitis C virus infection. J Infect Dis 2003; 188: 62-65. 